\title{
Persistencia de la India en Octavio Paz
}

\author{
Fabienne Bradu
}

Este ensayo revisa la presencia de la India en la literatura del poeta Octavio Paz, usando para ello la metáfora del palimpsesto, de capas de sentido y de experiencia sobrepuestas. Para esto se revisa la estancia del poeta en la India como parte de una cierta "educación sentimental", a partir de obras como $\mathrm{La}$ dera este, El mono gramático y Vislumbres de la India.

Palabras clave: Octavio Paz, India, literatura.

This essay reviews the presence of India on the literature of the poet Octavio Paz, using for this aim the metaphor of palimpsest, with layers of sense and experience superimposed. With this purpose, we review the poet's stay on India as part of a certain "sentimental education", starting from works like Ladera este, El mono gramático and Vislumbres de la India.

Keywords: Octavio Paz, India, Mexican literature.

Fecha de recepción: 27 de enero de 2012

Fecha de aceptación: 26 de abril de 2012 

Fabienne Bradu

Instituto de Investigaciones Filológicas

Universidad Nacional Autónoma de México

\section{Persistencia de la India en Octavio Paz}

Octavio Paz recuerda que en alguna ocasión Nehru comparó la India con un palimpsesto, en el que "uno debajo del otro, están inscritos muchos hechos, ideas y sueños, sin que ninguno de ellos cubra completamente a los que están abajo" (Vislumbres de la India, 146). El símil podría perfectamente extenderse a la presencia de la India en la creación del poeta mexicano. La estancia de Octavio Paz en la India fue "una educación sentimental, artística y espiritual", dice él en Vislumbres de la India. "Su influencia puede verse en mis poemas, en mis escritos en prosa y en mi vida misma" (26). Más que una influencia libresca, la India selló su vida hasta tal punto que no vaciló en escribir: "Fue un segundo nacimiento" (26). Conjunción del azar y del destino, la fórmula sintetiza la visión que tiene Octavio Paz de su propia vida, de la creación poética y de ciertos resortes de la historia, así como nombra el lugar donde, más que ningún otro, se le ofreció la conjunción que indistintamente expresa como "reconciliación" (El mono gramático) o "renacimiento" (Vislumbres de la India). "Fue un período dichoso [recapitula a más de cuarenta años de distancia] sobre todo, allá encontré a la que hoy es mi mujer, Marie-Jo, y allá me casé con ella" (26). Pero antes de ahondar en el balance final, la gran suma de experiencias vitales y poéticas, rehagamos, junto con el poeta, sus primeros pasos por la India en una madrugada de noviembre de 1951, poco después de que el Battory atracara frente al muelle de Bombay. 
En efecto, once años antes de la estancia decisiva en calidad de Embajador de México, Octavio Paz se asomó por unos meses (1951-1952) al vértigo de mundo que "mother India" descubre a los ojos del visitante como una vislumbre del caos original y como si una civilización pudiera ser todavía la vulva abierta del cosmos. Octavio Paz llegaba de París, "una ciudad en donde la mesura rige con el mismo imperio, suave e inquebrantable, los excesos del cuerpo y los de la cabeza" (5). Aunque allí su trato más asiduo hubiese sido con los surrealistas, únicos sobrevivientes de la imaginación libertaria entre la intelectualidad sartreana y estalinista de la postguerra, Octavio Paz arribaba de un mundo de mesura, de ordenada transparencia y de geometrías haussmanianas. En el preámbulo a Vislumbres de la India, Octavio Paz se empeña en recrear su primer día en Bombay bajo la forma de una enumeración caótica: una pura acumulación de imágenes en párrafos apretados y espaciados entre sí por unos blancos que semejan vacíos atónitos del pensamiento, una suspensión de toda tentativa de reflexión sistemática, que calcan de manera inmejorable el primer contacto de un extranjero con la India. Cuando la primera noche se cerró sobre el hervidero de imágenes, Octavio Paz le pidió amparo a un árbol para recapitular los sucesos del día:

Me senté al pie de un gran árbol, estatua de la noche, e intenté hacer un resumen de lo que había visto, oído, olido y sentido: mareo, horror, estupor, asombro, alegría, entusiasmo, náuseas, invencible atracción. ¿Qué me atraía? Era difícil responder: Human kind cannot bear much reality. Sí, el exceso de realidad se vuelve irrealidad pero esa irrealidad se había convertido para mí en un súbito balcón desde el que me asomaba ¿hacia qué? Hacia lo que está más allá y que todavía no tiene nombre... (16).

Es asombroso cómo, desde el recuento del primer día, Octavio Paz anticipa algunos de los temas esenciales de su poesía contemporánea del período indio: la interpelación de todos los sentidos para aprehender el mundo - "le dérèglement de tous les sens" que pretendía Rimbaudy que, poco a poco, sobre todo en la segunda y prolongada estancia, lo conducirá a una afortunada fusión entre el yo y la naturaleza, a estrechar, hasta lo imposible, la distancia entre las palabras y las cosas; el exceso de realidad que, tras el aparente caos y una primera sensación 
de extrañeza extrema, comienza a hacerle intuir que su percepción desbordará los cauces de la razón y del conocimiento, y lo llevará hasta el ojo de un huracán donde las dualidades violentamente contrastadas se aniquilan y los tiempos coinciden en uno solo: el presente perpetuo de la poesía.

También se advierte que, desde el primer día y, diría, de un modo inconsciente o intuitivo, Octavio Paz pide amparo a los árboles de la India. Años después, en Cuento de dos jardines, la misma petición se precisa: "Nosotros le pedimos al nim que nos casara". Recordemos asimismo La higuera religiosa o un singular y breve poema de Ladera este: "Dónde sin quién" que encierra una pequeña clave y constituye, sin duda, uno de sus más bellos poemas de amor. Octavio Paz lo escribe después de la partida de Marie-José de la India y antes de reencontrarla en el milagroso cruce de dos calles parisinas. Dice el poema:

$$
\begin{aligned}
& \text { No hay } \\
& \text { ni un alma entre los árboles } \\
& \text { Y yo } \\
& \text { no sé adónde me he ido (384). }
\end{aligned}
$$

Como suele suceder en la obra de Octavio Paz, el relato autobiográfico se disemina y se disimula entre la maleza ajena. Así, en un comentario sobre la poesía de Henri Michaux, se esconde una confesión que escapa del gran recuento de la India. Octavio Paz cuenta:

Experimenté una sensación parecida (la visión del caos), aunque mucho menos intensa y que afectó sólo a las capas superficiales de mi conciencia, en el gran verano de la India, durante mi primera visita, en 1952. Caído en la gran boca jadeante, el universo me pareció una inmensa, múltiple fornicación. Vislumbré entonces el significado de la arquitectura de Konarak y del ascetismo erótico. La visión del caos es una suerte de baño ritual, una regeneración por la inmersión en la fuente original, verdadero regreso a la "vida anterior" ("Henri Michaux", 246).

La India toma por asalto al viajero, incluso al más letrado y conocedor de sus tradiciones, y nadie puede sustraerse al golpe de estado que significan estas vislumbres del caos. Uno cree que no entiende nada 
cuando, en realidad, apenas comienza a entenderlo todo, quizá a recordar lo que siempre supo y olvidó.

Del primer y breve período en la India atestiguan los poemas " $\mathrm{Mu}-$ tra" y "El balcón". Acerca del primero, Octavio Paz puntualizó en 1995 que lo escribió para defenderse de la tentación metafísica de la India. Y junto con "Vrindaban" de 1963, asegura Octavio Paz que ambos poemas son la expresión instintiva y defensiva del moderno activismo occidental. No parece casual que una de sus primeras impresiones de la India se cifre en el título "El balcón". Octavio Paz todavía percibe y describe Dehli — "Dos sílabas altas/rodeadas de arena e insomnio"- desde la balaustrada del balcón, es decir, desde una distante altura.

Sin embargo, a mitad del poema, una evocación de Delhi parece nacer de un amor próximo a la compasión más honda, a la compenetración con una decadencia y una descomposición, que compone uno de los retratos más acertados de la ciudad:

\author{
Vieja Delhi fétida Delhi \\ callejas y plazuelas y mezquitas \\ como un cuerpo acuchillado \\ como un jardín enterrado \\ Desde hace siglos llueve polvo \\ tu manto son las tolvaneras \\ tu almohada un ladrillo roto \\ En una hoja de higuera \\ comes las sobras de tus dioses \\ tus templos son burdeles de incurables \\ estás cubierta de hormigas \\ corral desamparado \\ mausoleo desmoronado \\ estás desnuda \\ como un cadáver profanado [...]
}

(“El balcón”, Ladera este, 345).

Octavio Paz introduce, en boca del poeta chino Lin-Yu, una extraña advertencia: "No te apoyes, / si estás solo, contra la balaustrada" (344), 
que quiero leer como una premonición en el sentido más amplio de la poesía visionaria, como Novalis le pedía que fuera a la verdadera poesía. Octavio Paz tenía que esperar la aparición del amor, la presencia encarnada de la semejanza entre poesía y amor, para aventurarse en una inmersión irrestricta en el mundo de la India. "Algo se prepara", escribía el poeta en una fría noche de París, una puerta estaba a punto de abrirse y él sabía que la única puerta que permite la reconciliación o el renacimiento es la del amor. Cuando habla de la escultura clásica de la India como un predominio de las curvas y las ondulaciones. Irradiación carnal pero habitada, por decirlo así, por una indefinible espiritualidad. Estatuas que son de este mundo y del otro, también habla de su propio tránsito por el cruce único, vertiginoso e irrepetible entre erotismo y espiritualidad. Hacia el final de su vida, le dedicó un largo ensayo: $L a$ llama doble, pero el germen y la floración tuvieron lugar en los días de la India, durante la estación violenta.

Cabría detenerse un poco sobre esta experiencia de la espiritualidad y la declarada defensa contra la metafísica de la India. Para no confundir la espiritualidad de Octavio Paz con alguna forma de religión o religiosidad que nunca abrazó, podría recordarse un comentario que, a propósito de otro poeta, parece resumir su convicción profunda:

La experiencia divina es participación en un infinito que es medida y ritmo. Fatalmente vienen a los labios las palabras agua, música, luz, gran espacio abierto, resonante. El yo desaparece pero en el hueco que ha dejado no se instala otro Yo. Ningún dios sino lo divino. Ninguna fe sino el sentimiento anterior que sustenta a toda fe, a toda esperanza ("Henri Michaux", 247-248).

A mi juicio, estas palabras son las que más se reiteran en los poemas de Ladera este y también son las que guían el camino reflexivo que sube a Galta en El mono gramático. Octavio Paz dice, años después, que Vislumbres de la India es una tentativa por responder a la pregunta que hace la India a todo aquel que la visita. Nunca explicita cuál es la pregunta, pero por lo que sucede en Galta y por la observación de las cosas empeñadas en ser, nada más en ser, podemos colegir que la pregunta va más allá del occidental ¿quién soy? y se reduce a un simple y más complejo: ¿soy? 
En otro poema de Ladera este, "Felicidad en Herat", Octavio Paz confiesa su "fracaso metafísico" cuando sube a la cúpula turquesa del Jardín de las Señoras:
No tuve la visión sin imágenes,
no vi girar las formas hasta desvanecerse
en claridad inmóvil,
el ser ya sin sustancia del sufí.
No bebí plenitud en el vacío
ni vi las treinta y dos señales
del bodisatva cuerpo de diamante (365).

En cambio, lo ganado es más que lo perdido, y el fracaso se vuelve así una victoria inesperada:

\author{
Vi un cielo azul y todos los azules, \\ del blanco al verde \\ todo el abanico de los álamos \\ y sobre el pino, más aire que pájaro, \\ el mirlo blanquinegro. \\ Vi al mundo reposar en sí mismo. \\ Vi las apariencias. \\ Y llamé a esa media hora: \\ Perfección de lo Finito (365).
}

La espiritualidad de Octavio Paz se arraiga en el exceso de realidad que Galta le revela aquella tarde, a la luz de las seis de la tarde, un día cualquiera entre el "pellejo de piedras" y la "montaña sarnosa". Un poco más adelante, va precisando la visión y el instante:

Todo resplandece: las bestias, las gentes, los árboles, las piedras, las inmundicias. Un resplandor sin violencia y que pacta con las sombras y sus repliegues. Alianza de las claridades, templanza pensativa: los objetos se animan secretamente, emiten llamadas, responden a las llamadas, no se mueven y vibran, están vivos con una vida distinta de la vida. Pausa universal: respiro el aire, olor acre de estiércol quemado, olor de incienso 
y podredumbre. Me planto en este momento de inmovilidad: la hora es un bloque de tiempo puro (El mono gramático, 491).

Así vemos cuán lejos está Octavio Paz del vuelo metafísico, entre caricaturesco y colorido, vaporoso y florido, que los hippies de su tiempo fueron a buscar a la India. La verdadera espiritualidad de la India no consiste en una fuga de la realidad sino en su revelación por el exceso; no reside en un chapuceo de metafísicas manoseadas por las modas y los malestares de la civilización occidental, sino en una viva relación cotidiana de su pueblo con un cosmos concreto, por no decir prosaico. Cuando Octavio Paz habla de la experiencia de lo divino como "ninguna fe sino el sentimiento anterior que sustenta a toda fe, a toda esperanza", es esto mismo que observa en los peregrinos que se aparecen aquella tarde en Galta: "Alegría de la confianza: se sentían como niños entre las manos de fuerzas infinitamente poderosas e infinitamente benévolas" (494). Es, a mi criterio, una de las expresiones más atinadas y perspicaces de la espiritualidad que se advierte entre los habitantes de la India.

La realidad que revela la poesía y que aparece detrás del lenguaje [reflexiona Paz en El mono gramático] es literalmente insoportable y enloquecedora [...]. Es la percepción necesariamente momentánea (no resistiríamos más) del mundo sin medida que un día abandonamos y al que volvemos al morir (509).

En esto consiste, para mí, la gran revelación espiritual y poética que la India significó para Octavio Paz. Si bien esta búsqueda había estado presente desde los inicios de su poesía y su reflexión ensayística, la India le descubrió el palpable ritmo del infinito que es el que sentimos latir en toda su producción poética de la época y que culmina en Blanco. "Cada uno tiene el infinito que merece", afirma Octavio Paz en otra ocasión. "Pero ese mérito no se mide con nuestras medidas" ("Gracia, ascetismo, méritos", Excursiones/Incursiones, 248).

Al mencionar estas palabras, no puedo dejar de recordar la ironía con que el entonces secretario de Relaciones Exteriores de México, Manuel Tello, le propuso el puesto de embajador en la India. Cuenta el propio 
Octavio Paz en Itinerario: "Manuel Tello lo hizo con cierta abrupta franqueza y en estos términos: 'No le puedo ofrecer nada sino la India. Tal vez usted aspire a más pero, teniendo en cuenta sus antecedentes, espero que lo acepte"' (109). Por más que Octavio Paz asegure que no hay mérito capaz de sancionar el infinito que cada cual alcanza, quiero ver en la humildad y el entusiasmo con que aceptó el cargo, una señal de lo que le sería deparado en materia poética y personal. Una embajada modesta, entonces deslucida, a cambio de un reino donde, como aseguró André Breton, es verdad que el más allá, todo el más allá está en esta vida, toda la maravilla está en este mundo.

Para comprobar que la India selló su vida hasta el fin de sus días, quisiera concluir con uno de los últimos poemas que Octavio Paz escribió. Ahora forma parte de un volumen póstumo, Figuras y figuraciones (1999), que reúne algunos collages de Marie-José Paz y poemas alusivos, compuestos para la ocasión por su marido. Se titula, precisamente, "India":

Estas letras y líneas sinuosas que en el papel se enlazan y separan como sobre la palma de una mano: ¿son la India?

Y la pata de metal leonado - forjado por el sol, enfriado por la lunasu garra que oprime una dura bola de vidrio y la esfera iridiscente donde arden y brillan los millares de velas que, cada noche, los devotos lanzan a navegar por lagos y por ríos: ¿son una profecía, un acertijo, la memoria de un encuentro, los signos dispersos de un destino?

- Son el cetro del azar. Lo dejó, al pie del árbol del tiempo, el rey de este mundo (18). 
Para muchos de nosotros, amigos y lectores de Octavio Paz, la India es un país que primero descubrimos en la obra del poeta. Y si hoy seguimos atraídos y fascinados por este subcontinente, gran parte de la culpa la tiene Octavio Paz. Va a continuación una prueba de ello.

Posdata peregrina: El camino a Galta

Y la olorosa llama se alzaba

Hacia la luz divina, su hermana celeste.

\section{Luis Cernuda}

A fines del año 2000, el poeta Manuel Ulacia y yo volvimos de un largo viaje a la India, a Nepal, a Tibet y al diminuto reino de Buthan. Fue como recorrer porciones del pasado y, sobre todo, reencontrarse con uno mismo, en las formas imprevisibles y a menudo vicarias que brindan los viajes. Dice san Juan de la Cruz que uno no viaja para extraviarse sino, al contrario, para encontrarse al cabo de unos caminos que bien podrían emular el vuelo de los pájaros de Attar en busca del rey Simurg. En El parlamento de los pájaros, el poeta y místico iraní asegura que el rostro que se descubre en el espejo al concluir el viaje, es el rostro de uno. "Siempre caminamos al encuentro de..., aunque sepamos que nada ni nadie nos aguarda", escribe Octavio Paz en El mono gramático (465) rehaciendo con palabras el sendero que sube a Galta. Sin embargo, Manuel y yo acariciábamos la ilusión de que algo nos esperaba en Galta.

Fue lioso llegar hasta allí. El brillo y el bullicio de Jaipur opacan el secreto de Galta. Nadie comprendía por qué estábamos dispuestos a sacrificar una visita a un feérico palacio con tal de ir a morder el polvo de Galta. Intentamos explicar que un poeta mexicano..., que un libro de poesía..., que Hanuman y El mono gramático... Finalmente, el más iletrado de todos, nuestro incondicional chofer Gopal, fue quien entendió que una poderosa razón nos atraía hacia Galta. Hacia el final de la tarde, el blanco y rutilante Ambassador gobernado por Gopal y la sombra tutelar de Ganesh, enfiló hacia El mono gramático. Mentiría si dijera que entramos a Galta por el camino que traza Octavio Paz en su libro. Todo era, a un tiempo, familiar e inédito. Nos adentramos en 
la memoria de un libro en el que un poeta inventa su propia memoria del lugar donde aparentemente sucede el libro que nos aprestábamos a releer con nuestros pasos. Centenares de monos aguardaban en la entrada del antiguo santuario. Compramos cacahuates para distraer la emoción que nos despertaba penetrar hasta el corazón del libro. Los monos se acercaban, saltaban, reían, pelaban los dientes para merecer con una gracia un cacahuate. Uno que otro se nos quedaba viendo con la misma mirada de azoro con que lo veíamos a él. Un grupo de sadhus abandonaba el santuario; quizá acababan de realizar sus abluciones crepusculares en el estanque de Galta. En la avenida central, entre los palacios que contemplan sus respectivas ruinas, unos niños esperaban a improbables compradores de las chucherías esparcidas sobre las piedras. Nos metimos a un edificio que parecía ser el principal y cobijaba varios altares alrededor de un patio cuadrado y recién lavado. Sobre un costado, desde un cuarto que podía ser público o privado, subía la voz de un rezo. Nos asomamos a la puerta: allí estaba sentado el sacerdote obeso y seboso, con larga barba entrecana y rizada, el torso desnudo hasta la cintura, que custodia una página de $E l$ mono gramático. Quizá alentados por el inconsciente reconocimiento, le preguntamos por “¡Hanuman!”, sin saber bien a bien qué queríamos decir o pedir a través de este nombre. El sacerdote cerró las páginas de un voluminoso libro cubierto con la hiedra caligráfica del sánscrito y nos preguntó qué veníamos a buscar a Galta. Manuel volvió a hilvanar el mismo semblante de explicación: un poeta mexicano, un libro de poesía, un mono gramático, y añadió unas inconexas palabras acerca de la amistad, la memoria, la muerte de un poeta. El otro escuchaba y sudaba. Quedamos en silencio los tres. El sacerdote parecía meditar nuestro asunto o simplemente intentaba descifrar nuestras confusas explicaciones. Al cabo de un rato, llamó a otro sacerdote o sadhu que andaba por allí y algo le ordenó. Nos invitó a seguir al otro y regresó a su lectura. Obedientes y agradecidos, pusimos nuestros pasos tras las pantorrillas escuálidas del hombre. Cruzamos cuartos oscuros, torcimos por pasillos estrechos que figuraban un laberinto, hasta desembocar en un cuartucho más oscuro y como aceitoso, donde apenas cabíamos los tres. El aire enrarecido olía a una mezcla de sudor y de incienso. El hombre mascullaba un inglés de circunstancia. Con un 
dedo señaló una llama que ardía en una copa ennegrecida. “¡Hanuman!", gritó moviendo el índice. "Esta llama arde desde hace quinientos años", añadió en voz más baja. Luego señaló una pasta de sándalo anaranjado y con el pulgar nos preguntó si queríamos que nos marcara el entrecejo. Accedimos. Las palabras le faltaban a él y a nosotros nos sobraban. Depositamos unas rupias a un lado de la piedra pintada de rojo y salimos en silencio.

Afuera el sol no terminaba de ponerse. En un lapso de El mono gramático, Octavio Paz habla de "un resplandor sin violencia y que pacta con las sombras y sus repliegues [...] los objetos se animan secretamente, $[\ldots]$ no se mueven y vibran, están vivos con una vida distinta de la vida" (491). El mismo resplandor caía sobre los mismos palacios ruinosos, el mismo estanque hediondo al pie de la montaña, los mismos monos, el mismo polvo y las mismas piedras. ¡Cuánta razón tiene Octavio Paz en sustituir la palabra quietud, inasible e imprecisa, por la de persistencia! Galta era, esa tarde, la viva encarnación de la "persistencia de las cosas, de las ruinas, de la luz". Para nosotros que llegábamos a Galta casi cuarenta años después de Octavio Paz, la persistencia era más palpable aún. También se sumaba la persistencia de la memoria que, gracias a nosotros, revivía un libro y a un poeta. No éramos sino lectores, algo fetichistas lo admito, pero también peregrinos que sin proponérselo cumplían un peculiar ritual de poesía viva.

Seguimos deambulando por Galta. Cerca de una eremita en lo alto de una montaña donde un baba había pasado una vida meditando tal vez sobre la persistencia del espíritu, un mono saltó a mis espaldas y me arrancó de las manos el cucurucho de periódico con los cacahuates. Reímos de su astucia y de mi susto. Bajamos a comprar más cacahuates y dedicamos el resto del paseo a jugar con los monos.

No sé qué pasó aquella tarde en Galta. No sé qué íbamos a buscar, menos aún qué encontramos. Quizá no había tesoro escondido, ningún secreto que elucidar, nada salvo "la persistencia de las cosas, de las ruinas, de la luz". Nada salvo la doble memoria que cargábamos y vivíamos a un mismo tiempo, y que torpemente intento reconstruir aquí. Quizá no importe averiguarlo porque, como lo asegura Octavio Paz, "la poesía no quiere saber qué hay al fin del camino" (516). 


\section{REFERENCIAS}

PAz, Octavio, "Gracia, ascetismo, méritos", en Obras completas, 2. Excursiones/ Incursiones. Dominio extranjero, México, Fondo de Cultura Económica, 1994, pp. 249-252.

Paz, Octavio, "Henri Michaux", en Obras completas, 2. Excursiones/Incursiones. Dominio extranjero, México, Fondo de Cultura Económica, 1994, pp. 243-247.

PAZ, Octavio, Vislumbres de la India, México, Seix Barral, 1995.

PAz, Octavio, Itinerario, México, Fondo de Cultura Económica, 1995.

PAZ, Octavio, El mono gramático, en Obras completas, 11. Obra poética I (1935-1970), México, Fondo de Cultura Económica, 1997.

Paz, Octavio, Ladera este, en Obras completas, 11. Obra poética I (19351970), México, Fondo de Cultura Económica, 1997.

Paz, Octavio y Marie José PAz, Figuras y figuraciones, Barcelona, Galaxia Gutenberg, 1999. 